\title{
Accompanying Symptoms in Vestibular Migraine
}

\author{
Sintomas Acompanhantes na Enxaqueca Vestibular
}

Aline Turbino Neves Martins da Costa Daniel Guedes Tomedi Camila Naegeli Caverni Larissa Mendonça Agessi Rosemeire Rocha Fukue Henrique Ballalai Ferraz Thais Rodrigues Villa

Universidade Federal de São Paulo

\section{*Correspondence}

Aline Turbino Neves Martins da Costa

E-mail: alineturbino@gmail.com

Received: May 6, 2019.

Accepted: May 17, 2019.

\section{ABSTRACT}

Objective: The aim of this study was to classify the patients with vestibular migraine into the subgroups with and without aura, and to evaluate the occurrence of the accompanying symptoms of migraine in each subgroup. Methods: A prospective study performed at a tertiary center of vestibular migraine, with patients fulfilling definitive diagnostic criteria for vestibular migraine through International Classification of Headache Disorders ICHD-3 $\beta$. Patients were stratified in the subtypes with and without aura, and the accompanying symptoms were verified in each subgroup. Results: A total of 143 patients were included, 124 women and 19 men ( $86 \%$ and $13 \%$, respectively). The mean age of onset of migraine in the patients ranged from 4 to 71 years (SD: 16.0) with a mean of 23 years, and an average headache frequency of 17 days per month (SD: 19.6), with a visual analog scale mean of 7.45 (SD: 1.88). Of the 143 patients evaluated, 101 (70\%) had ICHD-3 $\beta$ criteria for the diagnosis of migraine with aura. In patients with the migraine subgroup with aura, we found a higher relative risk for nausea $2,78(\mathrm{Cl}$ : 0.15-1.0; p0.04), vomiting, 2.65 (Cl: 1.26-5.55; p0.009), phonophobia 3,546 (1,6477,637, p0,001), osmophobia 3,016 (1,219-7,462, p0,014), kinesiophobia, 2,391 (1,128$5,071, p, 021)$, tinnitus 2,275 (1,062-4,873, 032), aural fullness 3,934 (1,519 - 10,192, p0,003), motion sickness associated with dizziness 3,924 (1,415-10,881, p0,006). Conclusion: In our center, migraine with aura was the most frequent subtype of migraine in patients with vestibular migraine. During the head attacks, some associated symptoms were more likely to occur in the aura subgroup, among them: nausea, vomiting, phonophobia, osmophobia, kinesiophobia, tinnitus, aural fullness and motion sickness accompanied by dizziness. In our sample, vestibular migraine associated with migraine with aura showed a higher risk of associated symptoms, suggesting that this subgroup is more severe, and with a more disabling disease.

Keywords: Migraine with aura; Migraine without aura; Vertigo; Vestibular disorders; Dizziness.

\section{RESUMO}

Objetivo: O objetivo deste estudo foi classificar os pacientes com enxaqueca vestibular nos subgrupos com e sem aura e avaliar a ocorrência dos sintomas associados à enxaqueca em cada subgrupo. Métodos: Estudo prospectivo realizado em um centro terciário de enxaqueca vestibular, com pacientes preenchendo critérios diagnósticos definitivos para enxaqueca vestibular por meio da Classificação Internacional de Distúrbios da Dor de Cabeça ICHD-3 $\beta$. Os pacientes foram estratificados nos subtipos com e sem aura, e os sintomas associados foram verificados em cada subgrupo. Resultados: Foram incluídos 143 pacientes, 124 mulheres e 19 homens ( $86 \%$ e 13\%, respectivamente). A idade média de início da enxaqueca nos pacientes variou de 4 a 71 anos (DP: 16,0), com média de 23 anos e frequência média de cefaleia de 17 dias por mês (DP: 19,6), com média da escala visual analógica de 7,45 (DP: 1,88). Dos 143 pacientes avaliados, 101 (70\%) apresentavam critérios ICHD-3 $\beta$ para o diagnóstico de enxaqueca com aura. Nos pacientes com subgrupo de enxaqueca com aura, encontramos maior risco relativo de náusea 2,78 (IC: 0,15-1,0; p0,04), vômitos 2,65 (IC: 1,26-5,55; p0,009), fonofobia 3.546 ( 1.647-7.637, p0.001), osmofobia 3.016 (1.219-7.462, p0.014), cinesiofobia, 2.391 (1.128-5.071, p, 021), zumbido 2.275 (1.062-4.873, 032), plenitude auricular 3.934 (1.519 - 10.192, p0.003), enjoo de movimento associado a tontura 3.924 (1.415 - 10.881, p0.006). Conclusão: Em nosso centro, a enxaqueca com aura foi o subtipo mais frequente de enxaqueca em pacientes com enxaqueca vestibular. Durante os ataques na cabeça, alguns sintomas associados apresentaram maior probabilidade de ocorrer no subgrupo aura, entre eles: náusea, vômito, fonofobia, osmofobia, cinesiofobia, zumbido, plenitude aural e enjoo acompanhados de tontura. Em nossa amostra, a enxaqueca vestibular associada à enxaqueca com aura apresentou maior risco de sintomas associados, sugerindo que esse subgrupo é mais grave e com uma doença mais incapacitante.

Descritores: Enxaqueca com aura; Enxaqueca sem aura; Vertigem; Distúrbios vestibulares; Tontura. 


\section{INTRODUCTION}

Vestibular migraine (VM) is one of the variants of migraine, with vestibular symptoms (VS) beyond the typical disease model, with a lifetime prevalence of $1 \%$. It is the most common cause of episodic vertigo and the second most frequent cause of vertigo in general. ${ }^{2}$

Studies on vertigo and dizziness showed a prevalence of $4 \%$ to $51.7 \%$ among patients with migraine. ${ }^{3}$ A tertiary neuro-otology center studied the epidemiology of vestibular disorders and their clinical form and found $28.2 \%$ of patients with VM. ${ }^{4}$

Many authors have already demonstrated the association between migraine and vestibular symptoms, which are three times more common in the migraine population. $^{2}$

The International Headache Society (IHS) has included in an appendix, in 2013, the third edition of the International Classification of Headache Disorders a first step towards the identification of new entities. ${ }^{5,6}$ (Table 1)

The accompanying symptoms are part of the diagnostic criteria for both migraine and vestibular migraine and may be responsible together with vestibular symptoms for the significant impact on patients' quality of life. ${ }^{7}$

Table 1. VM diagnostic criteria - ICHD-B $\beta$ diagnosis

Definite $\mathbf{V}$
1.
mod least five episodes with vestibular symptoms of a
hours.
Current or previous history of migraine with or without
2. aura according to the International Classification of
Headache Disorders (ICHD).
One or more migraine features with at least 50\% of the
vestibular episodes:
- Headache with at least two of the following
characteristics: one-sided location, pulsating quality,
moderate or severe pain intensity, aggravation by
routine physical activity;
- Photophobia and phonophobia;
- Visual aura.
Not better accounted for by another vestibular or ICHD
diagnosis.

Photophobia, phonophobia, nausea, and vomiting are present in the diagnostic criteria of $\mathrm{VM}$ and should accompany at least $50 \%$ of the episodes of dizziness. ${ }^{5-6}$

The association of VM with subtypes of migraine, migraine with and without aura, and its association with accompanying symptoms has not been consistently analyzed in the literature.

\section{OBJECTIVE}

To classify the patients with definitive diagnosis of VM in the subtypes of migraine with and without aura and to evaluate the accompanying symptoms of each subgroup.

\section{METHODS}

A prospective study carried out in a tertiary VM outpatient clinic at the Federal University of São Paulo, from Jan 2014 to July 2016, by a neurologist specialized in headache, where demographic data was collected, as diagnosis of the migraine subtypes and accompanying symptoms.

We evaluated 198 patients with vestibular symptoms and headache, and 55 patients were excluded. All patients included had diagnostic criteria for definitive VM by ICHD-3 $\beta$, and the neurological and otoneurological examination of these patients was normal.

We excluded 55 patients, where dizziness could be attributed to systemic causes, or to patients with neurological diseases (epilepsy, stroke) and vestibular, as well as those who used ototoxic medications, chronic alcoholics, patients with a history of drug addiction, previous history of otologic diseases (antecedent of repeated ear infections, ear trauma) and cranial injuries.

Audiometric examination and computerized cranial tomography were performed, before inclusion of the patients. Patients with low-frequency sensorineural hearing loss were excluded, as well as patients with ischemic lesions in neuroimaging

Regarding statistics, we first characterized the sample collected by calculating frequencies and percentages or means and standard deviations. Patients were then divided into migraine without aura and migraine with aura and the rates and the percentages were obtained for each group.

The groups were compared with respect to the follow-up symptoms, using the chi-square test ${ }^{7}$ and, if necessary, the Fisher's exact test. ${ }^{8}$. Odds ratios (OR) and respective $95 \%$ confidence intervals $(95 \% \mathrm{Cl}$ ) were also calculated. ${ }^{8}$

The statistical package used was Minitab, version 18.

This research was approved by the Ethics Committee of the University and the patients completed the Informed Consent Term.

\section{RESULTS}

Of the 198 patients evaluated, 55 were excluded with a definitive diagnosis of VM. Thus, the group consisted of 124 women and 19 men ( $86 \%$ and $13 \%$, respectively). The mean age of onset of migraine in patients ranged from 4 to 71 years, with a mean of 23 years (SD16), with a mean frequency of 17 days of headache per month (SD10.8). Of the 143 patients with VM, 101 (70\%) had ICHD-3 $\beta$ criteria for migraine with aura (MA) and 29\% (42) for migraine without aura (MWO) (Table 2).

As for the type of aura, 87 (86\%) patients presented visual aura, 31 (30\%), sensory aura and 3 (2.9\%), motor aura (Table 3).

Concerning pain intensity assessed by visual analog scale (VAS), a mean of 7.45 (SD1.88) was obtained.

During VM crises, we evaluated some accompanying symptoms in the subgroups of migraine with and without aura. The symptoms were more frequent in VM with aura. 
Table 2. Demographic and clinical characteristics of patients with migraine

\begin{tabular}{lccc}
\hline Variable & $\mathbf{N}$ & Mean & SD \\
\hline Age (years) & 143 & 37.83 & 17.66 \\
$\begin{array}{l}\text { Age at headache onset } \\
\text { (years) }\end{array}$ & 143 & 23.13 & 16.08 \\
$\begin{array}{l}\text { Pain duration (hours) } \\
\text { Pain frequency (days) }\end{array}$ & 143 & 15.43 & 9.92 \\
month) & 143 & 17.52 & 10.82 \\
Daily headache (months) & 143 & 13.53 & 19.68 \\
Pain intensity (VAS) & 143 & 7.45 & 1.88 \\
Sex & & Female & Male \\
& & $86.71 \%$ & $13.29 \%$ \\
Aura & & with aura & without aura \\
& & $70.63 \%$ & $29.37 \%$ \\
\hline
\end{tabular}

SD: standard deviation, VAS: visual analog scale.

Table 3. Frequency distribution of the variable Type of aura

\begin{tabular}{lcccc}
\hline \multirow{2}{*}{ Type of aura } & \multicolumn{2}{c}{ Yes } & \multicolumn{2}{c}{ No } \\
\cline { 2 - 5 } & $\mathbf{n}$ & $\%$ & $\mathbf{n}$ & $\%$ \\
\hline Visual aura & 87 & 86,14 & 14 & 13,86 \\
Sensory Aura & 31 & 30,69 & 70 & 69,31 \\
Motor aura & 3 & 2,97 & 98 & 97,03 \\
Others & 2 & 1,98 & 99 & 98,02 \\
\hline
\end{tabular}

$\mathrm{n}$ : number of patients.

In the MA subgroup we found a higher relative risk for: nausea 2,788 (1,020 - 7,623, p0,040); vomiting 2,655 (1,269-5,557, p0.009); phonophobia 3,546 (1,647 - 7,637, $\mathrm{p}=0.001)$, osmophobia 3,016 (1,219 - 7,462, p = 0,014), kinesiophobia 2,391 (1,128 - 5,071, $\mathrm{p}=0,021)$, tinnitus 4,273 (1,215 - 15,049, $p=3,934$ (1,519-10,192, $p=0.003)$, motion sickness associated with dizziness $3,924(1,415-$ 10,881, $\mathrm{p}=0.006$ ) (Table 4).

\section{DISCUSSION}

The migraine association with aura and $\mathrm{MV}$ remains controversial. In the study by Calhoun et al. ${ }^{9}$, which aimed to determine and characterize the prevalence of dizziness in migraine, 425 patients were evaluated, of which $28 \%$ had MA. The prevalence of dizziness was twice as high (24.5\% vs $12.1 \%$ ) in migraine with aura compared to migraine without aura $(P<0.01)$. Prevalence also increased with age $(P<0.05)$.

Another study ${ }^{10}$ evaluated the prevalence of vertigo, dizziness, and VM over the years in patients diagnosed with migraine, comparing them with a control group. Both groups were assessed for symptoms of dizziness and vertigo.

The study included 327 patients diagnosed with migraine with and without aura and 324 controls with no history of a frequent headache. 199 (60.9\%) patients had migraine with aura (MA), 128 (39.1\%) migraine without aura (MWA).

Patients of the MA subgroup had, more frequently, vertigo symptoms/dizziness than those with MWA. Of the 199 patients in the MA subgroup, 19 (14.84\%) always reported vertigo symptoms/dizziness associated with headache, than those of the MWA 19 subgroup (9.55\%) reported. Patients in the MA subgroup had a higher association with dizziness and vertigo $(P<0001)$.

In Neuhauser's study"1 4869 patients were evaluated on the epidemiology of MV in the general population. In this sample 33 patients had VM, being 36\% MA and 64\% MWA, and after regression analysis of migraine with aura, it was not a risk factor for $\mathrm{VM}$.

In the study by Cohen et al,(12), they identified predictive factors of the VM of the 147 individuals, 100 (68\%) were women and 47 (32\%) men aged 15 to 92 years (mean age 45 years). Of the 147 evaluated, 57 (39\%) had migraine with aura and 90 (61\%) had no aura;

Table 4. Joint frequency distribution between patient characteristics and VM and migraine groups with aura and without aura, $\mathrm{p}$-value of the chi-square test, odds ratio and respective $95 \%$ confidence interval.

\begin{tabular}{|c|c|c|c|c|c|c|c|c|}
\hline \multirow{3}{*}{$\begin{array}{l}\text { Variables } \\
\text { Nausea }\end{array}$} & \multicolumn{2}{|c|}{ Without aura } & \multicolumn{2}{|c|}{ With aura } & \multirow{3}{*}{$\begin{array}{c}\text { P Value } \\
0,040\end{array}$} & \multirow{3}{*}{$\begin{array}{c}\text { Odds ratio } \\
2,788\end{array}$} & \multirow{2}{*}{\multicolumn{2}{|c|}{$\begin{array}{c}\text { Confidenc } \\
\text { interval }\end{array}$}} \\
\hline & \multirow{2}{*}{$\frac{\mathbf{n}}{33}$} & \multirow{2}{*}{\begin{tabular}{c|}
$\%$ \\
78,57
\end{tabular}} & \multirow{2}{*}{$\begin{array}{c}\mathbf{n} \\
92\end{array}$} & \multirow{2}{*}{$\begin{array}{c}\% \\
91,02\end{array}$} & & & & \\
\hline & & & & & & & 1,020 & 7,623 \\
\hline Vomiting & 17 & 40,48 & 65 & 64,36 & 0,009 & 2,655 & 1,269 & 5,557 \\
\hline Phonophobia & 13 & 30,95 & 101 & 61,39 & 0,001 & 3,546 & 1,647 & 7,637 \\
\hline Photophobia & 14 & 33,33 & 51 & 50,50 & 0,060 & 2,040 & 0,963 & 4,322 \\
\hline Osmophobia & 7 & 16,67 & 38 & 37,62 & 0,014 & 3,016 & 1,219 & 7,462 \\
\hline Kinesiophobia & 14 & 33,33 & 55 & 54,46 & 0,021 & 2,391 & 1,128 & 5,071 \\
\hline Tinnitus & 3 & 7,14 & 25 & 24,75 & 0,016 & 4,273 & 1,215 & 15,049 \\
\hline Headache & 25 & 59,52 & 75 & 74,26 & 0,080 & 1,962 & 0,917 & 4,197 \\
\hline Aural fullness & 6 & 14,29 & 40 & 39,60 & 0,003 & 3,934 & 1,519 & 10,192 \\
\hline Hearing loss & 5 & 11,90 & 18 & 17,82 & 0,380 & 1,605 & 0,554 & 4,650 \\
\hline Motion sickness + headache & 6 & 14,29 & 30 & 29,70 & 0,053 & 2,535 & 0,967 & 6,647 \\
\hline Motion sickness + dizziness & 5 & 11,90 & 35 & 34,65 & 0,006 & 3,924 & 1,415 & 10,881 \\
\hline Motion sickness & 6 & 14,29 & 29 & 28,71 & 0,068 & 2,417 & 0,920 & 6,348 \\
\hline
\end{tabular}

Source: the author 
of the subgroup with aura 21 (37\%) were male and 36 (63\%) female. A significant difference was observed in the subgroups of migraine patients with vestibular symptoms: sensitivity to bright lights occurred in $74 \%$ of the subgroup with aura and $43 \%$ in the subgroup without aura ( $p$ <0001), motion sickness (51\% with aura and 39\% without aura) and climate changes (54\% with aura and $31 \%$ without aura), the differences approached but did not reach significance ( $P=0.08$ and .07 , respectively).

To investigate the clinical features of multiple diseases that involved vertigo/dizziness, Esch et al. $^{13}$ investigated 122 patients, and only 16 were diagnosed with VM, where the accompanying symptoms were evaluated. Of the patients, 7 (44\%) had aura, 16 (100\%) reported nausea, 7 (44\%) vomiting, 11 (69\%) photophobia and 11 (69\%) phonophobia, as well as asymmetric hearing loss in 12 (75\%) and tinnitus in 2 (13\%).

A study published in the Neurology Journal ${ }^{14}$ on VM, its clinical evolution and cochlear dysfunctions in a 9-year follow-up, followed 61 patients with the diagnosis. The accompanying symptoms were assessed at baseline and followed-up after nine years.

The most frequent accompanying symptoms at the initial evaluation were photophobia in 59\% of the patients and phonophobia in 54\%, during the 9-year follow-up, these symptoms were $80 \%$ and $77 \%$, respectively.

During VM crises, cochlear symptoms appeared in $49 \%$ of the patients, tinnitus in 33\%, auditory symptoms (tinnitus symmetrical, aural fullness) in $26 \%$ and hearing difficulty in $26 \%$. Initially, $18 \%$ of the patients reported aura and, during follow-up, $44 \%$ of the patients reported symptoms.

This study followed patients with a definitive diagnosis of VM for nine years, their accompanying and cochlear symptoms both at admission and during followup, showed worsening of symptoms also in the interictal period. It was possible to observe the appearance of aura during the patients' follow-up of the patients. The author of the publication suggests that the worsening of the evolution of symptoms, including in the interictal period, may be associated with a progressive deterioration of the vestibular system caused by the disease.

In our sample, patients with VM diagnosis of the aura subgroup had a higher chance of presenting nausea, vomiting, phonophobia, osmophobia, kinesiophobia, tinnitus, auricular fullness and motion sickness associated with dizziness. Photophobia, headache, hearing loss, headache-associated kinesis, and isolated kinesis were not associated with the MA subgroup.

There are, to date, no other studies correlating the odds ratio of the accompanying symptoms between the VM and the subgroups of migraine.

We must emphasize the significant size of this sample, and that this is a tertiary research center of VM. All patients were diagnosed by a neurologist specialized in headache and vestibular symptoms and met the criteria of VM according to ICHD-3 $\beta$.

Although there was no statistical difference between the groups (migraine with or without aura regarding vestibular symptoms), they appeared three times more in the subgroup with aura. However, because of the size of our sample, it may not be possible to state that having aura is a risk factor for developing vestibular symptoms. Thus, studies with larger populations should be carried out.

It is still relevant to note that, in the aura subgroup, the accompanying symptoms had a higher relative risk ratio for several accompanying symptoms, which demonstrates the greater severity and a more debilitating condition for this association of diagnoses.

Leão's cortical spreading depression ${ }^{15}$ in migraine with aura and neuronal hyperexcitability exacerbate the trigeminal activation process, thus causing neurogenic inflammation. This could contribute to the activation and sustained sensitization of this process, as well as cause reversible vasospasm of the internal auditory artery, responsible for vestibular symptoms, both during VM crises, and could also be responsible for damages in this pathway, which could justify vestibular symptoms, even during the interictal period. ${ }^{16,17}$

\section{CONCLUSION}

Patients with vestibular migraine and migraine with aura, when compared to patients with VM and migraine without aura, present a higher relative risk of having accompanying symptoms such as nausea, vomiting, phonophobia, osmophobia, kinesiophobia, tinnitus, auricular fullness, and motion sickness associated with dizziness.

Detailed anamnesis and the active search for the presence of aura, during the initial assessment and also during the evolution of the patient with $\mathrm{VM}$, are necessary, in order to diagnose vestibular symptoms. Diagnosing this subgroup with aura, where the accompanying symptoms are more frequent, makes them a group of patients with a more severe disease and with a worse prognosis.

\section{REFERENCES}

1. Stolte B, Holle D, Naegel S, Diener HC, Obermann M. Vestibular migraine. Cephalalgia. 2015 Mar;35(3):262-70. doi: 10.1177/0333102414535113.

2. Dieterich M, Obermann M, Celebisoy N. Vestibular migraine: the most frequent entity of episodic vertigo. J Neurol. 2016;263: 82-9. doi: 10.1007/s00415-015-7905-2

3. Cho SJ, Kim BK, Kim BS et al. Vestibular migraine in multicenter neurology clinics to the appendix criteria in the third beta edition of the International Classification of headache disorders. Cephalalgia. 2016;36(5):454-462. doi: 10.1177/0333102415597890.

4. Guerra-Jiménez G, Arenas Rodríguez A, Falcón González JC, Pérez Plasencia D, Ramos Macías Á. Epidemiología de los trastornos vestibulares en la consulta de otoneurología. Acta Otorrinolaringol Esp. 2017;68(6):317-22. doi 10.1016/j. otorri.2017.01.007.

5. Headache Classification Committee of the International Headache Society (IHS).The International Classification of Headache Disorders, 3rd edition (beta version). Cephalalgia. 2013 Jul;33(9):629-808. doi: 10.1177/0333102413485658.

6. Lempert T, Olesen J, Furman J, Waterston J, Seemungal B, Carey J, et al. Vestibular migraine: diagnostic criteria. J Vestib Res. 2012;22(4):167-72. doi: 10.3233/VES-2012-0453.

7. Bussab WO, Morettin PA. Estatística Básica. 8. ed. São Paulo: Editora Saraiva, 2013. 
8. Pagano M, Gauvreau K. Princípios de Bioestatística. São Paulo. Editora Pioneira Thomson Learning, 2004.

9. Calhoun $\mathrm{AH}$, Ford S, Pruitt AP, Fisher KG. The point prevalence of dizziness or vertigo in migraine - and factors that influence presentation. Headache: The Journal of Head and Face Pain. 2011;51(9):1388-1392. doi:10.1111/j.15264610.2011.01970.x

10. Vuković V, Plavec D, Galinović I, Lovrenčić-Huzjan A, BudišićM, Demarin V. Prevalence of vertigo, dizziness, and migrainous vertigo in patients with migraine. Headache: The Journal of Head and Face Pain. 2007 Nov-Dec;47(10):1427-35. doi: 10.1111/j.1526-4610.2007.00939.x

11. Neuhauser HK, Radtke A, von Brevern M, Feldmann M, Lezius $\mathrm{F}$, Ziese $\mathrm{T}$, et al. Migrainous vertigo: prevalence and impact on quality of life. Neurology. 2006;67(6):1028-1033. doi: 10.1212/01. wnl.0000237539.09942.06

12. Cohen JM, Bigal ME, Newman LC. Migraine and vestibular symptoms - identifying clinical features that predict "Vestibular Migraine". Headache: The Journal of Head and Face Pain. 2008;51(9):1393-1397. doi: 10.1111/j.15264610.2011.01934.x

13. van Esch BF, van Wensen E, van der Zaag-Loonen $\mathrm{HJ}$, van Benthem PPG, van Leeuwen R. Clinical characteristics of benign recurrent vestibulopathy: clearly distinctive from vestibular migraine and Meniere's disease?
Otol Neurotol. 2017;38(9):e357-e363. doi: 10.1097/ MAO.0000000000001553

14. Andrea $R$, von Brevern $M$, Neuhause $H$, et al. Vestibular migraine: long-term follow-up of clinical symptoms and vestibulo-cochlear findings. Neurology. 2012;79(15):160714. doi: 10.1212/WNL.Ob013e31826e264f.

15. Noseda R, Burstein R. Migraine pathophysiology: anatomy of the trigeminovascular pathway and associated neurological symptoms, cortical spreading depression, sensitization, and modulation of pain. Pain. 2013 Dec;154 Suppl 1:S44-53. doi: 10.1016/j. pain.2013.07.021.

16. Vass Z, Steyger PS, Hordichok AJ, Trune DR, Jancsó $G$, Nuttall AL. Capsaicin stimulation of the cochlea and electric stimulation of the trigeminal ganglion mediate vascular permeability in cochlear and vertebro-basilar arteries: a potential cause of inner ear dysfunction in headache. Neuroscience. 2001;103(1):189-201. doi: 10.1016/ S0306- 4522(00)00521- 2.

17. Vass Z, Dai CF, Steyger PS, Jancsó G, Trune DR, Nuttall AL. Co-localization of the vanilloid capsaicin receptor and substance $P$ in sensory nerve fibers innervating cochlear and vertebro-basilar arteries. Neuroscience. 2004;124(4):919-27. doi: 10.1016/j. neuroscience.2003.12.030. 